\title{
La imatge triomfal de sant Miquel i la propaganda del poder en la cultura festiva. Història de les festes d'acció de gràcies celebrades a València el 1711 per les victòries felipistes a Brihuega i Villaviciosa durant la Guerra de Successió
}

\section{Saint Miquel's triumphant image and the propaganda of power in festive culture. History of a thanksgiving feast celebrated in Valencia on 1711 for the victories of Philip V in Brihuega and Villaviciosa during the War of Succession}

\author{
Enric Olivares Torres \\ enrique.olivares@uv.es \\ Universitat de València
}

ORCID: 0000-0003-1120-698X

\begin{abstract}
Resum: L'article analitza la connexió simbòlica establerta a través de l'espectacle festiu entre la imatge del príncep de la milícia celestial, sant Miquel, i la del rei Felip V. La finalitat d'aquesta unió a través de la literatura, la imatge i la festa tenia com a objectiu principal el reforçament de la posició privilegiada del monarca com a enviat de Déu al temps que legitimava, a través de la seua visualitat i davant els seus vassalls, el poder absolut d'una monarquia que havia hagut de disputar en el camp de batalla. D'altra banda, la celebració d'una festa d'acció de gràcies per les victòries de Brihuega i Villaviciosa el 1711 esdevingué l'escenari idoni per a l'exhibició de mostres sinceres de lleialtat i fidelitat cap al monarca per part de la ciutat de València. La celebració valentina s'emmarcava en el context d'una Guerra de Successió que estava a punt de resoldre's a favor del Borbó.
\end{abstract}

Paraules clau: cultura festiva, sant Miquel, Felip V, València, Guerra de Successió

\begin{abstract}
The article analyzes the symbolic connection established through the festive spectacle between the image of the prince of the celestial militia, Saint Miquel, and that of King Philip V. The purpose of this union through literature, image and feast had as its main objective the strengthening of the privileged position of the monarch as sent from God while legitimizing, through his visuality and before his vassals, the absolute power of a monarchy that had to contend on the battlefield. On the other hand, the celebration of a thanksgiving party for the victories of Brihuega and Villaviciosa in 1711 was the ideal setting for the exhibition of sincere displays of loyalty and loyalty to the monarch by the city of Valencia. The Valencian celebration was framed in the context of a War of Succession that was about to be resolved in favor of Bourbon.
\end{abstract}

Keywords: festive culture, saint Michael, Philip V, Valencia, War of Succession 
Enric Olivares Torres. La imatge triomfal de sant Miquel i la propaganda del poder en la cultura festiva. Història de les festes d'acció de gràcies celebrades a València el 1711 per les victòries felipistes a Brihuega i Villaviciosa durant la Guerra de Successió.

\section{La victòria borbònica a Brihuega i Villaviciosa}

El 28 de setembre del 1710 l'arxiduc Carles d'Àustria, proclamat Carles III pels seus partidaris, entrà victoriós per segona vegada a Madrid. No obstant això, i com ja va esdevenir en la primera ocasió, el 1706, no pogué aprofitar aquell valuós avantatge estratègic per establir-se definitivament en el tron espanyol. Després de l'intent frustrat de controlar Castella i assetjades per l'exèrcit franco-espanyol de Lluís Josep de Borbó-Vendôme, les tropes lleials a l'arxiduc Carles van haver d'abandonar la capital el 9 de novembre del 1710. Quasi un mes després, el contingent comandat per James Stanhope, format per uns quatre mil o cinc mil homes, majoritàriament britànics, decidí fer nit a la localitat de Brihuega, en l'actual província Guadalajara. El dia següent, el 7 de novembre, es van veure aillats i envoltats per la cavalleria borbònica que els perseguia des de la seua eixida de Madrid. L'intens bombardeig de la vila i l'assalt de la infanteria, obligà els anglesos a una defensa ferotge, la qual cosa no va evitar la derrota i posterior rendició, ocorreguda dos dies després.

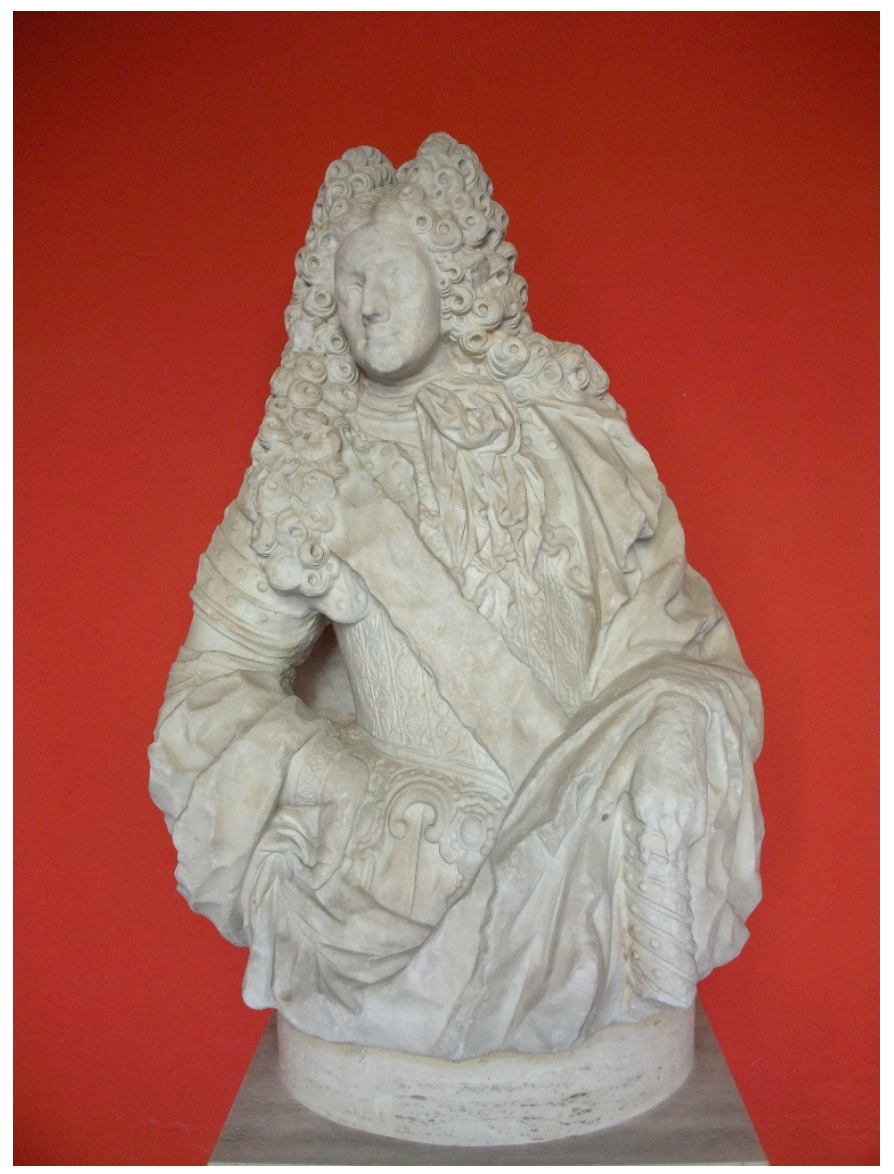

FIG. 1. Escultura de Felip V realitzada per Leonardo Julio Capuz cap al 1714 i conservada al Museu de Belles Arts de València, procedent del Pla de l'Albereda. 
Enric Olivares Torres. La imatge triomfal de sant Miquel i la propaganda del poder en la cultura festiva. Història de les festes d'acció de gràcies celebrades a València el 1711 per les victòries felipistes a Brihuega i Villaviciosa durant la Guerra de Successió.

Molt a prop, a Cifuentes, el gros de l'exèrcit austríac, dirigit per Guido von Starhemberg i constituiit per uns catorze mil efectius, se n'assabentà de la posició del comte de Stanhope -ja empresonat a Brihuega-i tornà enrere per tal d'ajudar-lo. Arribats el dia 10 a Villaviciosa de Tajuña, foren rebuts en posició de batalla per l'exèrcit enemic, format per uns vint mil soldats entre infanteria i cavalleria i al qual no pogueren fer front. ${ }^{1}$

Encara que finalment no hi hagué un guanyador clar de la batalla, la retirada de les tropes de Starhemberg cap a Saragossa i, després, fins a Barcelona, aquella fugida malparada, tot i que ordenada, fou considerada com una victòria del bàndol borbònic, ja que a la llarga decidí el resultat de la Guerra de Successió, l'abandonament dels aliats anglesos i holandesos i l'afiançament definitiu de Felip V en el tron d'Espanya. A partir d'aquell moment, l'acabament de la guerra es va precipitar ràpidament.

Les notícies de la victòria borbònica en la batalla, potser una de les més sagnants de tota la guerra, es difongueren de seguida i foren moltes les ciutats que ho celebraren amb sermons i festes d'acció de gràcies. Podem assenyalar els casos de Toledo, on la predicació eclesiàstica no deixà passar l'ocasió d'agrair la intervenció divina en tal desenllaç (Madrid 1710); Burgos, en què, a més de funcions religioses (Cubero 1711) hi hagueren màscares i representacions festives de caràcter civil (Castro 1711); però també Pamplona (Laguno 1710) o Sevilla (Arroyo 1711), on s'exaltà la causa borbònica i el feliç desenllaç que començava a intuir-se. ${ }^{2}$

L'Església, que no perdonava el pretenent austriacista per haver-la obligat durant la seua estada a Madrid a presentar inventari dels seus bens i subastar-ne una bona part, proclamà el caràcter de croada contra aquest $i$ els seus partidaris, especialment els anglesos, holandesos $i$ alemanys, titllats d'heretges i sacrílegs i, per tant, enemics de la vertadera fe (Martínez Gil 2011: 315).

Així les coses, podem observar com, tant les notícies arribades de les batalles de Brihuega i Villaviciosa com els sermons, les rogatives i les festes d'acció de gràcies se centraren de manera decidida en dos aspectes fonamentals. D’una banda, l'exaltació de Felip V com a vertader defensor de la fe catòlica, i d'altra, l'apel lació a la providència, i especialment a la Mare de Déu i els seus sants, com a protectors de la causa borbònica i agents especials dels seus triomfs.

La ciutat de València, que no va romandre aliena a l'esdeveniment, es disposà a festejar la victòria militar a començament del 1711. L'esquema celebratiu, especialment esplèndid, fou semblant al de dues ocasions anteriors: la conquesta de València per l'arxiduc Carles el 1706 i la recuperació de la ciutat per les tropes felipistes el 1707, dies després de la batalla d'Almansa. En totes tres se seguiren els models habituals acostumats a la ciutat al llarg dels segles XVI i XVII, però amb l'afegit d'incloure una processó general de gràcies que tenia com a destinació el convent de Sant Agustí, seu on es custodiava la imatge de la Mare de Déu de Gràcia. ${ }^{3}$

1 Recullen de manera pormenoritzada els fets ocorreguts en la batalla de Brihuega, entre altres, Castellví (2002: 102121 i 196-210) i Bacallar y Sanna (1957: 213-219).

2 Sobre aquestes celebracions i la seua difusió a través de la publicística vegeu Borreguero Beltrán (2003: 95-132).

3 Sobre els models celebratius d'aquest tipus de festes per victòries militars, vegeu Monteagudo Robledo (1995: 130-140).

SCRIPTA, Revista internacional de literatura i cultura medieval i moderna, núm. 17 / juny 2021 / pp. 117-138 ISSN: 2340-4841 · doi:10.7203/SCRIPTA.17.20735 
Enric Olivares Torres. La imatge triomfal de sant Miquel i la propaganda del poder en la cultura festiva. Història de les festes d'acció de gràcies celebrades a València el 1711 per les victòries felipistes a Brihuega i Villaviciosa durant la Guerra de Successió.

\section{La celebració a València d'unes festes d'acció de gràcies per la victòria del Borbó}

Pocs dies després de la desfeta austriacista arribaven les primeres notícies a la ciutat de València. Al seu diari, el cronista Josep Vicent Ortí i Major apuntava com el dijous 18 de desembre de 1710, dia de la Mare de Déu de l'Esperança i passades les quatre de la vesprada, se sentiren dispars i vol de campanes pels carrers per la notícia de la derrota a Villaviciosa i a Brihuega. També per la nit es feren lluminàries públiques amb protagonisme per al pregó que havia manat publicar la Ciutat i, afegia Ortí i Major, aquesta «estuvo muy regozijada» (Ortí i Major 1715: 1043, f. 322v; Escartí 2007: 300).

A més a més, durant tots aquells dies i nits posteriors es desplegaren tota una sèrie d'actes profans organitzats per les autoritats civils, funcions religioses per la victòria borbònica a la Basílica de la Mare de Déu dels Desamparats, així com oracions per les ànimes dels soldats caiguts en batalla al convent de Sant Doménech (Ortí i Major 1715: 1048-1049, f. 323r-324r; Escartí 2007: 301-302).

Fou acordada per la Ciutat i el capítol de la catedral la celebració d'una processó general de gràcies a la Mare de Déu, pel triomf de les tropes felipistes, la qual havia d'esdevenir-se el proper dia dels Reis, per estar massa prop les festes de Nadal. Tal com havia estat costum en ocasions semblants, es decidí que la processó havia d'anar a fer estació a la Mare de Déu de Gràcia, al convent de Sant Agustí. També s'assenyalaren diversos premis i lluminàries per tal que la ciutat es mobilitzara i adquirira una fesonomia pròpiament festiva i adequada per a l'esdeveniment.

Com transcorregué aquesta, ho sabem gràcies a dues relacions anònimes que han arribat fins als nostres dies. Una d'aquestes, titulada Demonstraciones festivas, que los leales afectos à su Magestad hiziieron dia de los Reyes del presente año 1711. en la Procession Solemne, que se hizo en gracias del feliz triunfo que ganò... Don Felipe V el Animoso, en la fortunada expedicion de Bribuega, y Batalla de Villaviciosa, fou atribuïda per Vicent Ximeno (1747: II, 312-313) a Josep Vicent Ortí i Major, autor també d'altres relacions de festes datades el 1719, 1731, 1738 i 1746, totes elles publicades anònimament. ${ }^{4}$

L'adhesió al bàndol borbònic, com es pot interpretar per l'evident to laudatori cap al monarca amb què s'expressava Ortí, li procurà en el seu moment la persecució i empresonament per Basset, en companyia d'altres desafectes a Carles III. Amb la victòria del Borbó, però, aquella demostrada fidelitat li aprofità per assolir alguns encàrrecs oficials així com la redacció de les citades relacions festives (Escartí 2007: 34-35), sent la més important de totes la dedicada per la Ciutat al cinqué centenari de la conquesta per Jaume I: Fiestas centenarias con que la insigne, noble, leal y coronada ciudad de

\footnotetext{
4 Relación individual de la venida de sus magestades y serenissimo principe don Luis a Valencia, y leales aclamaciones a su arribo, Josep Garcia, València, 1719; Relación del festivo y obsequioso recibimiento que hizo la ciudad de Valencia al sereníssimo señor infante don Carlos quando transitó por ella para proseguir su viage a la Italia, domingo, 11 de noviembre de 1731, València, 1731; Relación de las festivas aclamaciones con que celebró la ciudad de Valencia la noticia de los angustos desposorios del señor don Carlos Sebastián de Borbón y Farnese, infante de España y rey de las Dos Sicilias y Jerusalén con la sereníssima señora doña María Amelia Christina, princesa de Saxonia, hija de los reyes de Polonia, València, 1738 i Relación puntual de las fiestas con que la fidelíssima ciudad de Valencia acreditó nuevamente sus afectuosas demostraciones en la festiva proclamación de nuestro gran monarca el señor don Fernando VI de Castilla y III de Aragón, en los días 19, 20 y 21 de agosto de 1746, Viuda de Antonio de Bordázar, València, 1746.
}

SCRIPTA, Revista internacional de literatura i cultura medieval i moderna, núm. 17 / juny 2021 / pp. 117-138 ISSN: 2340-4841 $\cdot$ doi:10.7203/SCRIPTA.17.20735 
Enric Olivares Torres. La imatge triomfal de sant Miquel i la propaganda del poder en la cultura festiva. Història de les festes d'acció de gràcies celebrades a València el 1711 per les victòries felipistes a Brihuega i Villaviciosa durant la Guerra de Successió.

Valencia celebró el día 9 de octubre de 1738 la quinta centuria de su christiana conquista (Antonio Bordázar, València, 1740).

Descendent d'una important nissaga d'escriptors valencians, entre els quals destaca el seu avi, Marc Antoni Ortí i Ballester, notari i relator, entre d'altres, del Siglo quarto de la conquista de Valencia (1640), Segundo centenario de la canonización ... de San Vicente Ferrer (1656) i Solemnidad festiva ... canonización de Santo Tomás de Villanueva (1659), Josep Vicent Ortí i Major deixà una gran quantitat d'obra escrita: poesies, oratoris, obres dramàtiques, col loquis, lloes i actes sagramentals, així com també obres de caràcter hagiogràfic i històric. D'aquestes últimes, convé destacar les ja citades relacions de festes, en les quals segueix la tradició familiar, així com el seu Diario (1700-1715), on es comenten els moviments de les tropes borbòniques i els seus triomfs sobre les austriacistes dins el context valencià de la Guerra de Successió.

L'altra relació que ens parla d'aquelles festes, publicada amb títol de Resumen de las catolicas y leales correspondencias de Valencia, à los varios sucessos de la Reales armas del Rey nuestro Señor de 20 de agosto y 9 y 10 de diriembre 1710, sembla que fou obra, si seguim novament a Vicent Ximeno, de Josep Ortí i Moles, oncle de l'anterior i, com aquell, un apassionat partidari del duc d'Anjou.

Doctor en Lleis, arribà a opositar a una càtedra de Jurisprudència a la Universitat de València, ocupà l'ofici de secretari dels Estaments i regentà el Llibre de memòries de la Ciutat (Escartí 2007: 30-31). Segons Ximeno, fomentà l'estudi de les lletres i promogué la creació d'algunes acadèmies poètiques, «en las quales se empleavan muchos nobles y personas de habilidad y erudición» (Ximeno 1747: II, 211-212).

Tornats a les celebracions pel triomf dels de la beuté fleur, val a dir que la vespra del dia de Reis, es féu una encamisada o ball de màscares durant la nit. En ella es fingia una entrada dels tres Reis d'Orient, acompanyada per parelles amb ciris que anaven al davant a cavall. ${ }^{5}$ Assenyalava Ortí $i$ Major al seu diari que hi hagué distintes lluminàries, destacant-ne algunes, com les del convent de Sant Doménech, amb tretze mil llums -dos mil més n'afegirà la crònica de Josep Ortí i Moles-i on es podia llegir el nom del rei i les armes de la ciutat, també les de la parròquia de Sant Joan del Mercat, amb gran abundància sobre la torre del rellotge, i encara més les dels convents del trinitaris calçats i els agustins.

Així mateix, relatava Ortí i Major que el dia dels Reis hi hagué missa d'acció de gràcies a l'església metropolitana, en la qual predicà el canonge Jaume Servera, en presència de la imatge de la Mare de Déu dels Desemparats. Per la vesprada es féu la processó general de gràcies amb la imatge de la patrona, fins arribar a Sant Agustí, on féu estació a la Mare de Déu de Gràcia, com ja s’ha dit. Aquesta processó, que discorregué pels carrers del Rellotge i de Campaners, plaça de Santa Caterina i sant Vicent fins Sant Agustí i, des d'allí, pel carrer de la Mare de Déu de Gràcia, convent de la

5 A la seua relació d’aquestes festes, Josep Ortí i Moles afegeix que, a més d’aquesta encamisada, foren diverses les danses que discorregueren al llarg de la ciutat, parant a fer «sus vistosas, y diestras mudanças» davant les cases d'algunes autoritats locals (Ortí y Moles 1710: 21).

SCRIPTA, Revista internacional de literatura i cultura medieval i moderna, núm. 17 / juny 2021 / pp. 117-138 ISSN: 2340-4841 $\cdot$ doi:10.7203/SCRIPTA.17.20735 
Enric Olivares Torres. La imatge triomfal de sant Miquel i la propaganda del poder en la cultura festiva. Història de les festes d'acció de gràcies celebrades a València el 1711 per les victòries felipistes a Brihuega i Villaviciosa durant la Guerra de Successió.

Mercé, plaça del Mercat, Borseria i Cavallers fins a la Basílica dels Desemparats, s’inicià a la una del migdia i finalitzà a les sis de la vesprada i apuntava Ortí en el seu diari que festes a València com aquella no se n'havien vist de més cèlebres des de que es tenia memòria. L'església de Sant Agustí estava especialment decorada amb flors i llums en l'altar, capelles laterals i cornises. Tanmateix, en la volta de processó, els religiosos mercedaris van alçar un altar davant el seu convent, i un altre, a expenses de Pedro Villarejo, en la plaça del Mercat.

Per la seua banda, narrava Ortí i Moles que les parets, balcons i finestres dels carrers de la volta de processó es decoraren ostentosament amb llenços de gran primor, tapissos de gran riquesa, cortines i tafetans, així con un bon nombre de retrats del rei, la reina i el príncep.

\section{E1 seguici processional segons les relacions de Josep Ortí i Moles i Josep Vicent Ortí i Major}

Com hem dit, la processó d'acció de gràcies donà començament a la una de la vesprada amb els timbals, clarins i ministrils de la Ciutat. Anotava Ortí i Moles que els seguia un carro de triomf, el qual presentava en la part superior un tron format per un globus terraqüi i, en ell, les armes de la Ciutat, envoltat per panòplies militars, palmes, llorers i corones. Sobre ell, asseguda, estava representada l'al legoria de la Fama, amb el clarí d'argent com atribut. Sostenia en una mà una espasa i en l'altra un escut ornat amb fulles de llorer, en el qual figurava el retrat de Felip V. Als peus del tron una inscripció o motto inserida en una tarja explicava la figura:

La Fama el clarin suspende,/ pues de Filipo Animoso/ nuevo aliento, y mas glorioso/ Escudo es que nos defiende.

En el plànol de la carrossa s'havien col locat en cadascun dels angles quatre joves vestits amb diferents induments amb els quals representaven les Quatre Parts del Món, al temps que llançaven al públic versos impresos com l'anterior $i$ altres tants que adornaven la fàbrica del carro.

En un d'aquells fulls impresos es podien llegir diferents copletes en les quals es declaraven algunes idees que justificaven la celebració de la festa: l'agraïment de València al seu monarca, vencedor sobre l'heretgia als camps de Brihuega i Villaviciosa, i el reconeixement de la intercessió de la Mare de Déu i sant Miquel en l'obtenció de la victòria: ${ }^{6}$

\footnotetext{
A dàr Gracias à Maria,/ de tan singular vitoria,/ và la lealtad con gran gloria.

San Miguel es Capitan/ de tan lucido esquadron/ que guia esta Procession.

Si es Dios quien assiste al Rey,/ es segura la vitoria,/ que da assumpto à tanta gloria.

Que alegre voy con mi carro/ à dar gracias à Maria,/ de este tan plausible dia.
}

\footnotetext{
6 Un d'aquells fulls impresos amb versos es conserva a la Biblioteca Històrica de la Universitat de València davall la signatura Ms. $17 / 31$.
} 
Enric Olivares Torres. La imatge triomfal de sant Miquel i la propaganda del poder en la cultura festiva. Història de les festes d'acció de gràcies celebrades a València el 1711 per les victòries felipistes a Brihuega i Villaviciosa durant la Guerra de Successió.

Després d'aquest carro, seguien cinc roques del Corpus i sobre cadascuna d'elles anava una de les danses que la nit anterior havien ballat pels carrers de la ciutat, com era preceptiu en aquest tipus de celebracions. Una vegada acabaren de recórrer la volta de la processó, avançades com anaven respecte de la resta del seguici, aquestes danses baixaren de les respectives roques i tornaren a repartir-se al bell mig de la carrera per fer més festiu l'obsequi de la festa.

A continuació, darrere de les cinc roques encara vingué un altre carro triomfal més. Aquest de molt bella i ostentosa arquitectura, sobre el qual figurava un tron amb els retrats dels monarques. En la seua descripció, Ortí i Major resulta més prolix que el seu oncle, pel que seguirem el seu relat (Ortí y Mayor 1711: 2-9).

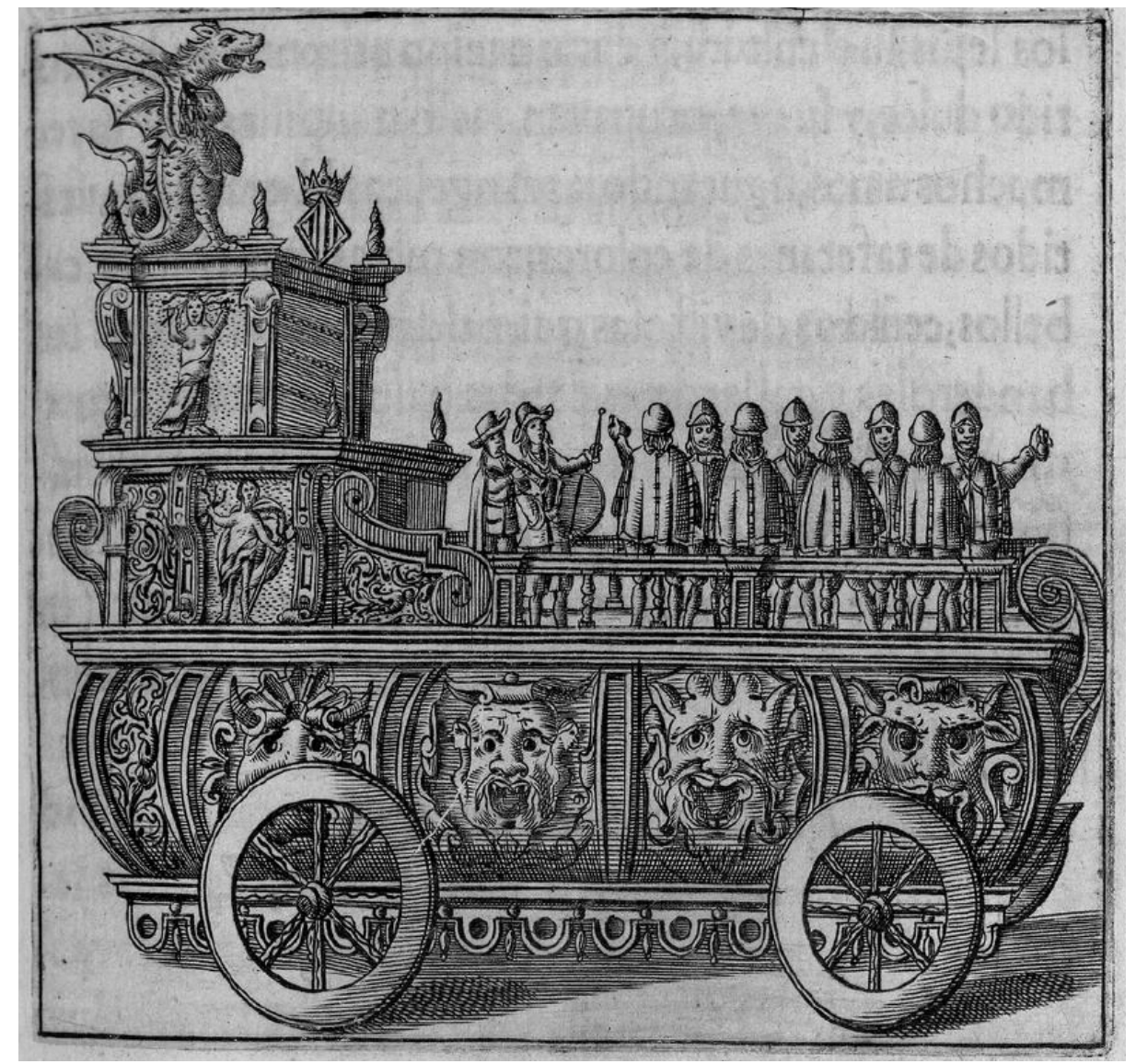

Fig. 2. Gravat d'un carro de triomf amb uns dansaires a la coberta, durant la celebració de les festes a la Immaculada el 1662, fet pel gravador F. Candi. Publicat a Valda, Joan Baptista de, Solenes fiestas que celebro Valencia a la Immaculada Concepcion de la Virgen. 
Enric Olivares Torres. La imatge triomfal de sant Miquel i la propaganda del poder en la cultura festiva. Història de les festes d'acció de gràcies celebrades a València el 1711 per les victòries felipistes a Brihuega i Villaviciosa durant la Guerra de Successió.

Aquest carro triomfal estava pintat amb motius de perfecta arquitectura i perfils daurats, i entreteixits a trets ben proporcionats hi havien fulles de llorer, estendards, banderes, panòplies $i$ altres elements militars, recursos metafòrics tots ells que feien al lusió al triomf en la batalla.

La proa del carro de triomf exhibia un cartell de grans dimensions amb forma de conxa, sobre la qual hi havia un banc on anava assegut el conductor. La popa, per la seua banda, mostrava un altre banc de bella inventiva i grandesa, sobre el qual descansava una vistosa galeria que coronava l'obra del primer cos de la carrossa. S'elevava al bell mig d'aquesta un majestuós tron de gran enginy i sobre ell estaven representats en dos migrelleus dos lleons que sustentaven el retrat del monarca. L'emmarcava una orla formada per estendards, banderes i timbals, així com altres atributs propis del déu Mart, tot decorat amb flors. A més, adornaven el carro huit targes on hi figuraven diferents versos.

En aquestes targes es projectaven diverses idees lligades a la celebració de la festa i justificatives de la mateixa que ens resulten de gran interés. El rerefons polític i devocional resultava evident. Una d'elles, per exemple, pretenia demostrar la lleialtat de València cap al duc d'Anjou:

Aunque este obsequio es pequeño/ à su heroyca Magestad,/ es hijo de la Lealtad.

Una altra afirmava que la victòria li havia estat concedida per la intermediació de la Mare de Déu:

A dar gracias à MARIA/ de tan singular victoria,/ và la Lealtad con gran gloria.

Una més destacava que la victòria no era només de Felip V sobre l'arxiduc Carles, sinó de les forces catòliques sobre les herètiques, representades aquestes últimes pels soldats anglesos:

Con mi espada, y con mi zelo/ defiendo mi Monarquia,/ contra heretica porfia.

Dins del carro i capitanejant-lo hi havia un jove macip, ricament vestit, la funció del qual era llançar els versos impressos al lusius al triomf del rei i a la festivitat que s'hi celebrava. Acompanyava el conjunt una música militar formada per clarins i timbals.

El carro estava tirat per sis cavalls, tots del mateix color i grandària, propietat del duc de Gandia, qui també havia cedit sis mules de recanvi. El seguien dos-cents acompanyants amb atxes i tancava aquest seguici un guió on apareixia pintat l'arcàngel sant Miquel, com a capità de l'exèrcit de Déu i del rei, i gràcies a l'assistència del qual el monarca devia un triomf tan transcendent.

A continuació, i darrere del guió, anaven altres cent torxes, a les quals seguia una companyia de xiquets disfressats d'àngels i en forma de milícia celestial, vestits d'argent i color blau celest i nacre i adornats amb ales de gran primor. Ornats aquests àngels amb joies, diamants, perles i cadenes d'or, tots portaven un ciri en una mà $i$ un escut en l'altra. En els diferents escuts es podien llegir 
Enric Olivares Torres. La imatge triomfal de sant Miquel i la propaganda del poder en la cultura festiva. Història de les festes d'acció de gràcies celebrades a València el 1711 per les victòries felipistes a Brihuega i Villaviciosa durant la Guerra de Successió.

algunes copletes al lusives a l'arcàngel i les seues victòries portentoses. I en aquest punt es dóna la feliç circumstància que dues de les publicades a la relació de Josep Vicent Ortí i Major estaven redactades en valencià, mentre que la resta ho estava en castellà:

Pues hui en gloria de Miquel,/ sols gracies ha de trobar;/ lo pes no ix pera pesar.

A vn temps van manifestant,/ los Cors dels Angels lo Cel,/ los cors dels homes lo Zel.

La majoria d'aquests versos buscaven exaltar la devoció cap a l'arcàngel com a capità de les milícies del cel, així com el seu paper intercessor en el desenllaç favorable de la victòria, i protagonista, junt amb la Mare de Déu en aquesta festa, per «afecto al Rey, y aplauso de la fiesta», recordava Ortí i Moles:

Miguel de la Fé es caudillo;/ buen Capitan eligieron/ los que al Rey le mantuvieron.

Així mateix, s'unia simbòlicament la idea del triomf de Felip V pel tron amb el triomf de l'arcàngel sobre el dimoni, i es reforçava la consideració que el d'Anjou era el vertader defensor del catolicisme front a l'heretgia protestant que representaven les forces angleses de l'arxiduc d'Àustria:

Pues tanto herege ha vencido,/ lo que en Philipo es victoria,/ en los Angeles es gloria.

Con las luzes arden juntos,/ al Santo el devoto ardor,/ à Philipo ardiente amor.

Al Rey, y à Miguel à vn tiempo,/ leales, y agradecidos, van constantes, y rendidos.

Logrò la primer vitoria/ Miguel, y aplaude en la tierra,/ à vna gloria de una guerra,/ otra guerra de otra gloria.

A més a més, a les idees anteriorment al ludides, les referències a la lleialtat de València cap al Borbó eren constants en aquests versos:

Oy celebran triunfo, que es/ del Rey, y de Religion,/ la Lealtad, y devocion.

Inmutable es la Lealtad;/ y de no dexar à vn Rey,/ San Miguel nos diò la Ley.

Si fue de Miguel el dia/ la gloria de esta Ciudad,/ oy le aplaude la Lealtad.

Seguidament, presidia aquella mainada angèlica un capità de la mateixa edat i també abillat com un esperit alat, el qual cridava profundament l'atenció. Bellament vestit a la manera de sant Miquel, mostrava sobre la celada una empresa molt adornada. En la mà dreta portava un bastó de comandament i en l'esquerra un escut, on hi figurava en lletres de corall sobre camp argentat el lema o timbre Quis sicut Deus que l'identificava com l'arcàngel.

Tota aquesta esquadra angèlica servia d'escorta a una imatge victoriosa de sant Miquel - de «singular primons, en paraules de Josep Ortí i Moles- conduïda sobre unes andes daurades per huit volants vestits també d'àngels amb gran lluïment. L'escultura estava adornada de joies, flors i plomes i amb ella es donava tancament a aquesta part de la processó. 
Enric Olivares Torres. La imatge triomfal de sant Miquel i la propaganda del poder en la cultura festiva. Història de les festes d'acció de gràcies celebrades a València el 1711 per les victòries felipistes a Brihuega i Villaviciosa durant la Guerra de Successió.

Val a dir que la representació d'una escorta de soldats no resultava cap novetat en el món de la festa i s'emmarcava en els paràmetres visuals de la celebració barroca. De fet, aquesta tradició ja venia de molt més lluny. Disposar una comparsa de guerrers amb el capità al voltant del tabernacle ha estat interpretat en ocasions com un record llunyà però encara viu de la pràctica de disposar la soldadesca a l'entorn del carro de l'emperador romà durant l'anomenada sparsio o llançament de diners entre la població -acte benèfic que provocava aldarulls i que calia evitar-. Així, l'esquadró angèlic no només es configurava com la mainada sagrada de l'arcàngel sinó també com la seua guàrdia pretoriana en la lluita contra l'enemic.

El per què d'una presència tan destacada de la imatge de l'arcàngel en aquest seguici el mateix Ortí i Moles la responia en la seua crònica, i no era altra que el fet que el 8 de maig del 1707, dia de la festa de l'Aparició de sant Miquel, la ciutat de València va ser rendida a les tropes de Felip V, i que el 28 de setembre del 1238, vespra de la festivitat de la Dedicació de sant Miquel, la mateixa ciutat va ser guanyada per Jaume I (Ortí y Moles 1710: 24):

\begin{abstract}
No fue sin fundamento este obsequio, pues en el dia de N. S. de los Desamparados del año 1707, en q la Ciudad se restituyò al Real dominio de el Rey nuestro Señor, concurriò ser tambien el dia que celebra la Iglesia la fiesta de la Aparicion de San Miguel; y à quien deviò la Ciudad ser la vispera de su otra festividad de la Dedicacion de S. Miguel el dia 28. de Setiembre de el año 1238. quando por el Señor Rey Don Jayme se librò de aquel yugo, y opresion de los Moros.
\end{abstract}

\title{
4. Descripció de la processó general
}

Tancada la part festiva de la processó amb la imatge devocional de l'arcàngel, la processó general ${ }^{7}$ s'obria amb les dues Banderoles de la Ciutat, les quals tradicionalment s'encarregaven de donar inici a aquestes. Les seguien els gremis amb les seues banderes, estendards i tabernacles amb les imatges dels seus patrons, així com l'acompanyament de la música de timbal i dolçaina, tal com era habitual.

Hi figuraven en aquella celebració els Cistellers, Traginers, Calderers, Matalafers, Corredors, Robers -aquests acompanyant la imatge del patró sant Jaume a cavall, portada per quatre homes vestits de turcs-, Cordoners, Barreters - amb la imatge de sant Jordi, també portada per quatre turcs («tambien propio trofeo de los triunfos que deve al Santo España contra los Moros», recordava Ortí i Moles en la seua crònica)-, i Guanters, amb la imatge de sant Bertomeu i una dansa de quatre Tornejants. Aquests amb vestits i empreses que representaven els quatre elements, precedits dels respectius padrins i amb la música d'un pifre i diverses caixes, mentre jugaven amb les vares al temps que realitzaven les mudances pròpies del Torneig (Ortí y Moles 1710: 28). ${ }^{8}$

\footnotetext{
7 Descripció el lidida per Ortí i Major en la seua relació i descrita, en canvi, pel seu oncle a la crònica corresponent.

$8 \mathrm{El}$ ball dels tornejants és una dansa ritual característica al territori valencià, hui en dia encara present a les poblacions riberenques d'Algemesí, Sueca i l'Alcúdia i davall la denominació dels Torners a Morella. La seua interpretació simula un enfrontament incruent on els dansaires juguen amb habilitat amb una vareta de faig a manera d'arma, la qual fan vibrar i enlairen amb coreografies de gran destresa. Present des del segle XVII en un bon nombre d'esdeveniments
} 
Enric Olivares Torres. La imatge triomfal de sant Miquel i la propaganda del poder en la cultura festiva. Història de les festes d'acció de gràcies celebrades a València el 1711 per les victòries felipistes a Brihuega i Villaviciosa durant la Guerra de Successió.

Darrere d'ells, continuaven els Tintorers -amb una imatge de l'arcàngel sant Miquel-, els Velers, els Forners -amb una dansa que acompanyava la imatge de la Mare de Déu de la Mercé-, els Tallants que tragueren un bou i una dansa- i després els Moliners - amb un carro de triomf que simulava un molí, en el qual alguns dels seus membres representaven les feines pròpies de la molta a la pedra-. A continuació processionaren els Obrers, els quals, com en altres ocasions festives, portaven la famosa Tarasca o Tortuga, la qual com a novetat presentava un sol i un arc de sant Martí sobre la seua closca. ${ }^{9}$ Continuaven els Esparters i Espardenyers, Cubers, Assaonadors, Soguers, Corretgers, Teixidors de lli i de llana, Ferrers, Manyans, Armers -amb la imatge de sant Martí i el pobre i una danseta de huit xiquets que l'acompanya-, Fusters, Sabaters, Sastres i Calceters, Blanquers i, finalment, els Peraires.

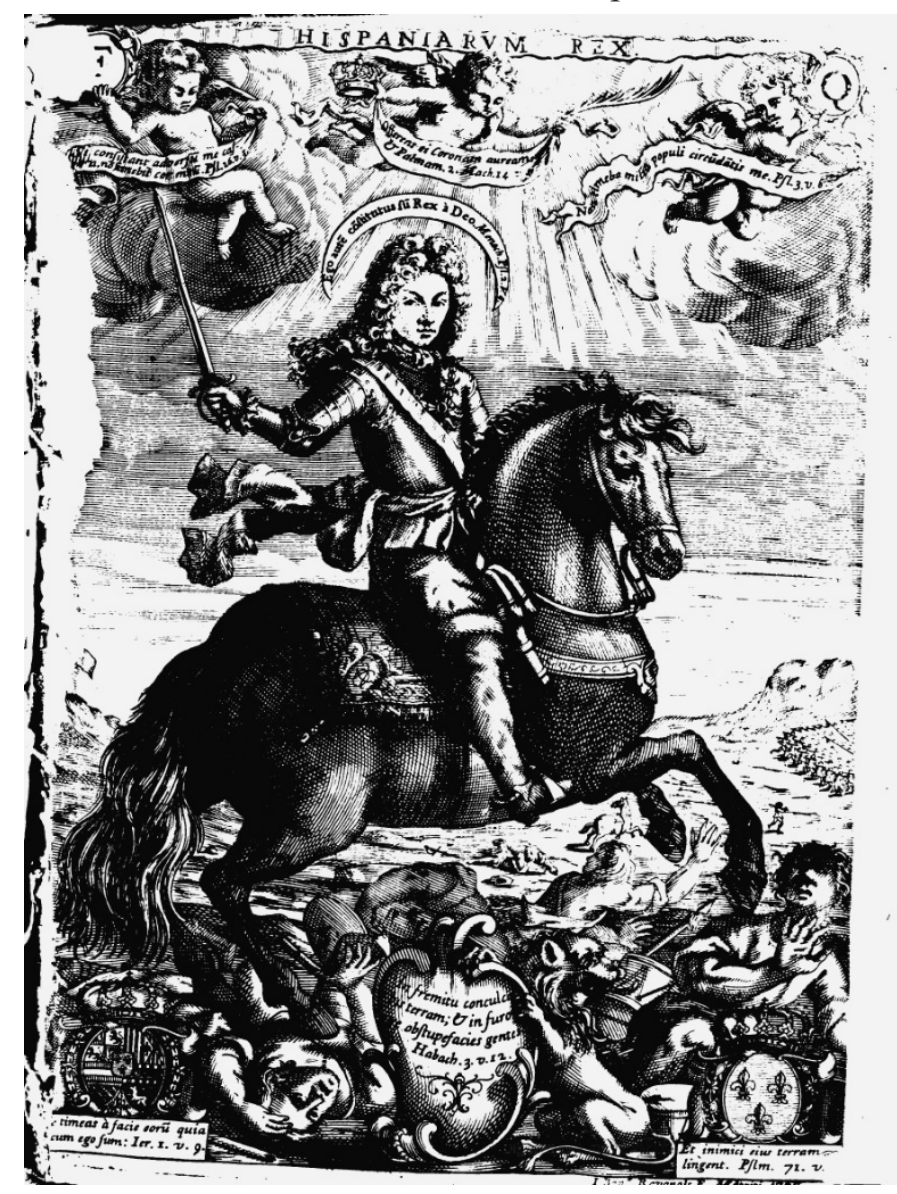

Fig. 3. Gravat de Joan Baptista Ravanals inclòs en l'obra d'Antonio Cabrera, Glorias de el señor D. Felipe Quinto, rey de las Españas... y fatales consequencias (1708), en què es representa el monarca com sant Jaume cavaller trepitjant els enemics.

festius de caràcter religiós i àulic, gaudí d’un notable predicament a la ciutat de València i a altres viles reials, com ara Alzira o Xàtiva. Vegeu Olivares Torres i Trescolí Bordes (2017: 65-75).

9 «Llevava sobre su concha vn lucido Sol, esparciendo rayos, y enfrente de èl vn Arco Iris de sus varios colores, con vn mote que corriea desde el Sol al Iris, que dezia: Mis triunfos la paz. anuncian». Ortí y Moles (1710: 29).

SCRIPTA, Revista internacional de literatura i cultura medieval i moderna, núm. 17 / juny 2021 / pp. 117-138 ISSN: $2340-4841 \cdot$ doi:10.7203/SCRIPTA.17.20735 
Enric Olivares Torres. La imatge triomfal de sant Miquel i la propaganda del poder en la cultura festiva. Història de les festes d'acció de gràcies celebrades a València el 1711 per les victòries felipistes a Brihuega i Villaviciosa durant la Guerra de Successió.

Als gremis de la ciutat els seguien la dansa de sis Nanos i els huit Gegants i, darrere d'aquests, la creu de la catedral, la qual donava començament al seguici de les comunitats eclesiàstiques, regulars i seculars, amb les seues respectives creus i imatges. Tancava la processó religiosa l'església metropolitana de València, amb les imatges de sant Lluís Bertran i sant Vicent Ferrer, i, darrer d'ells, la de la Mare de Déu dels Desemparats.

L'esquema celebratiu, doncs, mantenia el lluïment i fastuositat propis de les dècades anteriors, amb el qual es reforçava el sentit de la cohesió i la participació col lectiva dels distints estaments que configuraven la societat del moment, $i$ en el que les autoritats municipals i eclesiàstiques mostraven de manera multitudinària la seua fidelitat al poderós príncep cristià, un poder que esdenia ara, si més no, absolut.

Però no acabaren ací les festes d'acció de gràcies, sinó que els dies següents encara se celebraren funcions religioses per part d'alguns particulars, sent la més interessant de totes la que tingué lloc el 18 de gener, ja que en ella tornaren a participar els xiquets que s'havien vestit d'angelets en la processó del dia de Reis, amb un protagonisme destacat per a la imatge de sant Miquel arcàngel que tancava la part festiva d'aquella.

\section{La festa del dia 18 de gener de 1711}

Segons ens conta Ortí i Major en la seua relació, el diumenge 18 de gener fou tornada a la seua capella la imatge de sant Miquel que havien tret durant la processó de gràcies celebrada el dia de Reis. Es tractava d'una escultura de bella factura en la qual es representava el tipus iconogràfic de l'arcàngel vencedor del dimoni i que pertanyia a l'església del convent de Sant Cristòfol.

El desaparegut cenobi de Sant Cristòfol de les Nobles i Venerables Mares estigué ubicat fins a l'any 1868 en el carrer del Mar, entre els antics carrers del Torn de sant Cristòfol i de la Creu Nova. ${ }^{10}$ Renovat el 1672 , el temple presentava una única nau amb tres trams i capelles laterals. Segons la descripció que féu del temple el 1740 el jesuïta Jacint Ortí i Major, tercer fill de Josep Vicent (Ortí 1740: 96-100), ${ }^{11}$ les capelles de l'Evangeli estaven dedicades al titular, sant Agustí i sant Josep, respectivament, $i$ als peus de l'edifici se'n situava una altra de més menuda, davall del cor i dedicada a la Puríssima Concepció. En el costat de l'Epístola, per la seua banda, hi havia altres tres dedicades a la Mare de Déu, Crist Crucifixat i sant Antoni de Pàdua. Però ni

10 La seua fundació es troba indefectiblement unida a l'asalt del call ocorregut el 1391 i l'aparició miraculosa d'una imatge de sant Cristòfol en el subsòl de la sinagoga, on posteriorment s'alçà el convent, quan el 1409 i a instàncies dels jurats de la Ciutat es traslladaren unes religioses canongeses agustines procedents d'Alzira. Vegeu Pingarrón (1998: 332-333).

11 Nascut el 1702 i mort el 1745, el jesuïta Jacint Ortí i Major fou catedràtic i rector del Col legi de la Companyia a Sogorb.

SCRIPTA, Revista internacional de literatura i cultura medieval i moderna, núm. 17 / juny 2021 / pp. 117-138 ISSN: 2340-4841 $\cdot$ doi:10.7203/SCRIPTA.17.20735 
Enric Olivares Torres. La imatge triomfal de sant Miquel i la propaganda del poder en la cultura festiva. Història de les festes d'acció de gràcies celebrades a València el 1711 per les victòries felipistes a Brihuega i Villaviciosa durant la Guerra de Successió.

l'esmentat autor, ni altres posteriors, mencionen la ubicació que degué tindre la imatge de sant Miquel. D'ella tan sols tenim el testimoni succint del diari de Josep Vicent Ortí, on s'afirma que «era la que ay en la iglesia, en el nicho de su capilla», però poc més en sabem (Ortí y Mayor 1715: 1055, f. 324r-325v; Escartí 2007: 303). També gràcies a aquest diari coneixem la raó per la qual es féu aquella processó de tornada, i no en fou altra que per causa d'haver-se caigut la imatge a l'altura del carrer Borseria durant la processó del dia de Reis (Ortí y Mayor 1715: 1055, f. 324r-325v; Escartí 2007: 303):

Acompañáronla muchas achas y los niños se volvieron a vestir el trage de ángeles, como le
vistieron en la procesión; y la causa de no haverse vuelto antes fue porque en la procesión se
cayó de las andas al estar en la bolsería y se huvo de componer para poderle bolver al convento.

L'escultura eixí de la casa del marqués de Mirasol, qui processionà amb el seu fill, Joseph Carroz. El seguici desfilà al so de caixes i clarins, amb el mateix nombre de ciris, àngels i homes que en la funció anterior. Passà aquesta per diferents convents femenins: Caputxines, Encarnació, Santa Úrsula, la Puritat i les Magdalenes, fins arribar al de Sant Cristòfol. En tots ells, la imatge de sant Miquel fou rebuda amb vol de campanes, música d'orgue, llums en els altars i cors de veus que cantaven motets en honor de l'arcàngel.

En arribar finalment al convent de Sant Cristòfol, el personatge vestit de sant Miquel que capitanejava l'esquadró angèlic entonà un breu discurs d'acomiadament i agraïment als presents com a bons vassalls del rei, i a les religioses de Sant Cristòfol per la seua lliberalitat, desitjant per la salut del monarca i dels devots de l'arcàngel. Així finalitzà aquesta processó amb protagonisme per a l'arcàngel.

\section{El poder visual de la imatge de sant Miquel}

Com hem dit abans, l'escultura representava el conegut tipus iconogràfic de l'arcàngel vencedor del dimoni i que defineix la seua condició de cavaller en qualitat de príncep de les milícies celestials, ja que davall el seu comandament va combatre l'àngel rebel al principi dels temps i vencé el drac apocalíptic segons la profecia de sant Joan (Ap 12,7). Aquesta visualitat serví de model al relacionista de la crònica festiva per a comparar-la amb la victòria del primer Borbó sobre les tropes heretges que defensaven la causa austriacista i així afirmar sense por: «Quien como Philipo» (Ortí y Mayor 1711: 8), com si es tractés d'un alter ego del capità dels estols celestials.

Aquesta comparació ens porta a preguntar-nos per l'especial significació que la imatge militar de l'arcàngel sant Miquel tingué en aquesta celebració, en particular, però també per la devoció popular que es professava a la ciutat de València. 
Enric Olivares Torres. La imatge triomfal de sant Miquel i la propaganda del poder en la cultura festiva. Història de les festes d'acció de gràcies celebrades a València el 1711 per les victòries felipistes a Brihuega i Villaviciosa durant la Guerra de Successió.

En la seua condició de príncep i comandant de les milícies de Déu, la imatge guerrera de sant Miquel es va convertir durant segles en referent simbòlic a l'hora de demanar-li protecció front als poders del mal. El poder extraordinari de la seua figura explica la particular estima que al llarg dels temps li professaren emperadors i monarques arreu d'Europa. Evidentment, aquest tipus d'imatges revelen el paper fonamental de l'aparell icònic guerrer i triomfal de l'àngel guerrer per a les ideologies polítiques en la seua funció protectora sobre pobles i governants. Com a campió del cel, sant Miquel atorgava la victòria en la batalla a aquells que se li encomanaven. Per això, la seua ajuda fou freqüentment invocada per soldats, nobles i monarques, com pot veure's en diferents processos de conquesta en temps medievals. ${ }^{12}$

Així per exemple, alguna crònica de l'Edat Mitjana referia com el rei Pere I atribuí la seua victòria a Osca en la batalla d'Alcoraç el 1094 a la intervenció de sant Miquel ${ }^{13}$ (i no a sant Jordi com la majoria de cròniques afirmaven). També se li atribuí la seua ajuda al rei Alfons I el Batallador en la conquesta de Saragossa. ${ }^{14}$ Tanmateix, en caure la ciutat de Balaguer el 1101 aquesta quedà davall la seua protecció i es diu que Esnalbou fou reconquistada el dia de l'arcàngel del 1162. Com era costum, en temps de calamitats i perills la invocació als sants guerrers incloïa una petició d'ajuda i confiança en la victòria (Wittlin 1983: 17).

A València la devoció cap a l'arcàngel Miquel va adquirir una significació especial. La vespra de la seua festivitat de l'any 1238 la medina musulmana de Balansiya capitulava davant les tropes del rei Jaume I després d'un setge que havia durat cinc mesos. Aquells guerrers cristians van veure en la victòria davant els musulmans un acte de gratitud per part de l'arcàngel i per això no dubtaren en festejar-lo. A partir de llavors el seu culte fou especialment intens per part dels nous pobladors. Una de les mesquites de la València islàmica fou convertida i consagrada a ell i la campana més grossa del campanar de la catedral de València fou batejada amb el seu nom i amb ella el campanar, que rebé el nom de Micalet. Segles després, el cronista Escolano arribaria a afirmar la dignitat del fet que fóra considerat sant Miquel com el vencedor dels moros en la ciutat de València.

12 Alguns castells restaren davall l'advocació del sant, com ara Os de Balaguer, Tartareu, Aspremont, Mallabecs, Montllobar, Sant Llorenç de Morunys, etc. Vegeu Fité (1996: 23).

13 «E en aquell dia matex, fon la batalla de Anthioxia ab lo emperador de Alamanya. E per voler de nostre senyor Déu Jesuchrist, lo emperador (alemany) hac victòria e nostre senyor Déu, volent demostrar son poder e gran miracle he la insigne invocatió de monsényer sent Miquel, transportà, en un istant, de la batalla de Anthioxia, un cavaller alamany devot de sent Miquel, en lo qual se trobà [...] en la batalla ab lo rey en Pere en Aragó contra los moros, la qual batalla lo dit rey en Pere guanyà victoriosament contra los moros». Vegeu Puigpardines (2000: III, 46, 185).

14 Recull Ubieto Arteta aquesta tradició que conta com durant el setge de la medina musulmana de Saragossa per part del rei Alfons I d’Aragó, el bisbe de Pamplona vegé l'arcàngel Miquel sobre la muralla de la ciutat, figura envoltada d'una llum enlluernadora que brandava una espasa nua indicant als cristians que era voluntat de Déu que començaren l'atac per la porta assenyalada. Vegeu Ubieto Arteta (1999: 85-86). 
Enric Olivares Torres. La imatge triomfal de sant Miquel i la propaganda del poder en la cultura festiva. Història de les festes d'acció de gràcies celebrades a València el 1711 per les victòries felipistes a Brihuega i Villaviciosa durant la Guerra de Successió.

D'altra banda, el principal santuari regional dedicat a l'arcàngel fou el de Sant Miquel de Llíria. Fundat el 1326 per Jaume II. La creença popular va voler veure una obra de Jaume I en gratitud per la conquesta de València. Així mateix, el patrocini reial el detectem també en la fundació el 1546 pel duc de Calàbria de l'important monestir jerònim de Sant Miquel dels Reis per desig testamentari de la seua esposa, Germana de Foix.

En la segona meitat del segle XVII, en un moment de crisi política, econòmica, social i, sobretot, militar dins el context europeu d'aquell moment, el poder protector i la facultat providencialista per propiciar les victòries dels exèrcits cristians mogueren la monarquia espanyola a nomenar l'arcàngel sant Miquel tutor de la nació, en detriment de l'apòstol sant Jaume. La justificació d'aquesta proposta de patrocini nacional es trobava en un llibre publicat el 1643 pel pare Eusebio de Nieremberg, Devoción y Patrocinio de San Miguel, en el qual s'afirmava que l'arcàngel ja havia estat considerat com a patró militar de la península en temps dels visigots, per tant, molt abans fins i tot que ho fóra el Zebedeu. El jesuita, un dels principals valedors de l'arcàngel en aquest nou patrocini, féu una crida en aquesta obra al seu valor com a cavaller il lustre i com a exterminador dels infidels: «Tú eres las armas fortíssimas de nuestro Socorro [...]. Por ti los Reyes Catholicos alcanzan los trofeos de sus victorias. Por ti los Capitanes de los Exercitos del Pueblo Christiano vencen, y ignomiosamente deshacen las huestes de los infieles» (Nieremberg 1643: 4).

La conseqüència seria la declaració de dia festiu per les Corts de Castella el 8 de maig, dia de l'aparició de l'arcàngel. Nieremberg adduïa en la seua obra l'origen d'aquesta renovada fe a sant Miquel com a capità general dels exèrcits en la difusió d'una revelació del caputxí fra Severo de Tovar a Felip III vint anys enrere. Processons, sermons, resos i rogatives, així com també estampes, pintures i cartells impresos dedicats a l'arcàngel en favor de la Monarquia animaren i esteneren el seu fervor en un moment crític políticament per l'enfrontament amb Portugal. Així, per exemple, el pare mercedari Francisco del Espíritu Santo pronunciaria dècades després, concretament el 8 de maig de 1660 a Valladolid, un sermó favorable al seu patrocini contra els rebels a la Corona, en aquest cas, els portuguesos, equiparats per ell als pecadors contra Déu. ${ }^{15}$

15 Espíritu Santo, Francisco del, Sermón que el día de la aparición del invictísimo S. Miguel Arcángel..., Joseph Gómez de los Cubos, Salamanca, 1660. Citat per Bouza (2008: 152-155). 
Enric Olivares Torres. La imatge triomfal de sant Miquel i la propaganda del poder en la cultura festiva. Història de les festes d'acció de gràcies celebrades a València el 1711 per les victòries felipistes a Brihuega i Villaviciosa durant la Guerra de Successió.

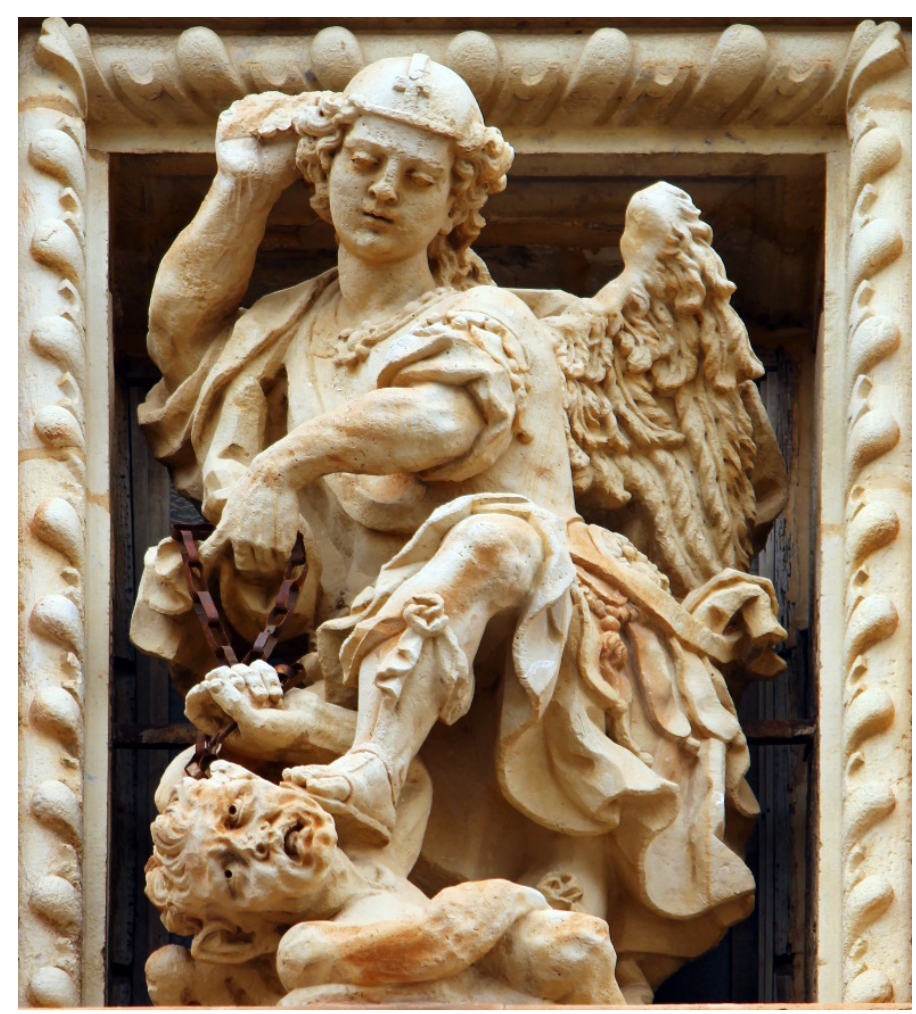

Fig. 4. Escultura de sant Miquel vencedor del dimoni, realitzada l'any 1700 per Raimundo Capuz a la façana retaule de l'església parroquial de l’Assumpció, a Llíria.

Les invocacions a la protecció de l'arcàngel i el record de les victòries guanyades gràcies al seu favor es mantingueren al llarg de la segona meitat del segle XVII, com ho demostra un altre exemple, un panegíric escrit pel pare jesuïta Francisco García titolat Elprimer ministro de Dios, san Miguel Arcángel. En ell, l'autor fa un repàs a les intervencions més decisives de l'àngel guerrer i les assimila a les batalles espirituals contra el dimoni, per això exhorta els governants a tindre'l com a advocat i protector especial (Garcia 1684: 15): ${ }^{16}$

\begin{abstract}
Por eso deben todos los Príncipe Christianos en las batallas contra los Infieles, y en las guerras justas con otros Principes, invocar à San Miguel; y todos los Capitanes, y soldados han de tener en particular Abogado, y Protector al Príncipe de la Milicia Celestial. Pero de mejor gana nos favorece en las batallas espirituales que tenemos con el mundo, demonio y carne y assí en nuestras tentaciones, le debemos invocar.
\end{abstract}

En aquest ambient de pietat popular i vist els antecedents propedèutics adjudicats a l'arcàngel sobre la ciutat de València, no resulta estrany que la seua figura sagrada tornara a ser utilitzada amb

16 Hi ha edició posterior publicada per Benito Monfort, Valencia, 1803, pàg. 31-33. 
Enric Olivares Torres. La imatge triomfal de sant Miquel i la propaganda del poder en la cultura festiva. Història de les festes d'acció de gràcies celebrades a València el 1711 per les victòries felipistes a Brihuega i Villaviciosa durant la Guerra de Successió.

sentit polític en les festives demostracions de gratitud realitzades el diumenge 19 de juny de 1707, en ocasió de les celebracions pel retorn de la ciutat i regne als dominis de Felip V, fet ocorregut el 8 de maig, dia de la Mare de Déu dels Desemparats i de l'Aparició de l'arcàngel sobre el Gargano.

Aquell 8 de maig, els jurats de la Ciutat eixiren a rebre les tropes felipistes comandades per Antonio del Valle i els lliuraren les claus per a evitar-ne el saqueig. Posteriorment, anaren a la basílica de la Mare de Déu dels Desemparats per donar gràcies i després es dirigiren a la catedral, on ressaren un Te Deum i seguidament passaren a les capelles de Sant Vicent Ferrer i de Sant Miquel a fer estació (Ortí y Mayor 1715: 575, f. 217r-218r; Escartí 2007: 215-216).

La celebració per la victòria començà la nit prèvia al 19 de juny. Hi hagué vol de campanes i lluminàries en els convents, parròquies $i$ cases particulars, $i$ en substitució d'un castell de focs es disparà una vistosa eixida de focs d'artifici des de la torre del Micalet. El matí del dia següent es traslladà la imatge de la Mare de Déu des de la seua basílica fins a la catedral, on es cantà missa conventual, amb assistència dels canonges, jurats, el comandant Antonio del Valle, el cavaller d'Asfeld i tota la noblesa valenciana, i predicà el canonge alzireny Jaume Cervera. D’aquest sermó diria en el seu diari Isidor Planes (1899: f. 189v $)^{17}$ que era digne de ser portat a la impremta, com així es va fer pocs dies després.

Com també ocorreria el 1711, per la vesprada es féu la processó general de gràcies al convent de Sant Agustí amb la imatge original de la Mare de Déu dels Desemparats per tal de fer visita a la imatge de la Mare de Déu de Gràcia, segons era costum en aquestes ocasions. Tant les cases com la portada del convent de Sant Agustí foren adornades, però res més ens diu Planes sobre les danses, carrosses, imatges -devocionals $\mathrm{i}$ àuliques- $\mathrm{i}$ associacions gremials $\mathrm{i}$ religioses que formaren el seguici, tot i que no deuria ser molt diferent a l'organitzat de tres anys després. Dóna alguna notícia més el Diario d'Ortí i Major, que no deixa de ser sucosa ${ }^{18}$ ja que apunta que en arribar la processó al convent de Sant Agustí es féu baixar d'una tramoia un xiquet, suposem que vestit d'àngel, amb una corona i un ceptre per deixar-los als peus de la imatge de la Mare de Déu. També afig que per la nit, a més de les lluminàries, el comte de Faura féu eixir un carro de triomf de la Ciutat decorat amb els retrats del rei i la reina, i dues comediantes assegudes en un tron que representaven el foc i l'aire i altres dues que figuraven la terra i l'aigua. Des d'aquest improvisat escenari cantaren una òpera d'uns tres quarts d'hora de duració en què els quatre elements competien per veure qui era el millor en celebrar el triomf del monarca.

Del sermó predicat pel canonge Cervera el matí del 19 de juny volem destacar breument el seu capítol V, en el qual justificava la intermediació de sant Miquel en aquest assumpte. Per a Cervera,

17 Vegeu també Ortí y Mayor (1715: 614, f. 227r-228r; Escartí 2007: 226-227).

18 Inclou Ortí una notícia d'especial interés. Conta que algunes comunitats de religiosos no acudiren a la processó, com fou el cas dels caputxins, que tant s'havien significat en la causa austracista. Vegeu Ortí y Mayor (1715: 614, f. 227r-228r; Escartí 2007: 226-227).

SCRIPTA, Revista internacional de literatura i cultura medieval i moderna, núm. 17 / juny 2021 / pp. 117-138 ISSN: 2340-4841 · doi:10.7203/SCRIPTA.17.20735 
Enric Olivares Torres. La imatge triomfal de sant Miquel i la propaganda del poder en la cultura festiva. Història de les festes d'acció de gràcies celebrades a València el 1711 per les victòries felipistes a Brihuega i Villaviciosa durant la Guerra de Successió.

l'arcàngel era «el Angel de las vitorias, el Arbitro de las guerras, y el Presidente de las batallas» (Cervera 1707: 17-24) i, per això, rebudes les súpliques, s'aconseguí recobrar la ciutat en el dia de la seua festa.

Les proves de la seua eficàcia foren exposades en el sermó. Primer amb exemples de l'Antic Testament: l'ajuda de l'arcàngel a Moisés per a lliberar el poble jueu de l'esclavitud a Egipte, la conquesta de Jericó pel cabdill Josué gràcies a la seua intervenció, l'aparició a Judes Macabeu muntat en un cavall i armat amb una llança i armes d'or per tal de derrotar l'exèrcit de Lisies, o la intermediació en el triomf del jutge Gedeó sobre els enemics madianites. A més dels oficis de l'antiga llei, i a partir dels textos dels escriptors eclesiàstics, Cervera desgranà altres intervencions militars en què l'arcàngel havia afavorit els monarques cristians, especialment francesos i hispànics, com ara Carlemany o Carles VII a través de Joana d'Arc en el setge d'Orleans. No passà per alt, per descomptat, el record de la conquesta de València per Jaume I la vespra del dia dedicat a la seua festivitat, ni el fet que un 8 de maig de 1701 els diputats i comissaris de les ciutats amb vot a les Corts castellanes prestaren jurament de fidelitat a Felip V en el convent dels jerònims de Madrid.

Aquesta relació simbòlica i visual de Felip $\mathrm{V}$ amb l'arcàngel encara tindria un episodi nou a València durant la celebració el diumenge 7 d'agost del 1707 d'una festa de rogatives a la Mare de Déu de l'Esperança en la parròquia de Sant Martí pel part de la reina Maria Lluïsa de Savoia. Per a representar la presència simbòlica dels monarques a l'acte es col locaren els seus retrats. L'escenificació de la mateixa volgué que el retrat de la reina estiguera situat immediat a la capella de l'Expectació, mentre que el del monarca se situà al costat de la capellà de l'arcàngel sant Miquel, en record, com tan acertadament apuntà en el seu Diario Josep Vicent Ortí i Major (1715: 652, f. 235r-235v; Escartí 2007: 234), del «que en el día dichoso de su aparición se restituyó Valencia a su legítimo dominio».

D'altra banda, i per a finalitzar, el paral lisme visual establert entre l'acàngel i Felip V com a combatent de l'heretgia no deixarà d'estar present en la propaganda política dels primers anys del seu regnat. Així, poc temps després, concretament el 1712, el pintor Felipe de Silva finalitzaria una pintura hui conservada en el Palau Reial d'Aranjuez titulada Felip V, Maria Lluïsa de Savoia i Lluís I combatent l'heretgia (Morán Turina 1990: 45). En ella, el monarca i el seu fill branden dues espases que dirigeixen contra un drac apocalíptic que profana alguns elements litúrgics del rite catòlic i que al ludeix evidentment als seus enemics protestants en la llavors encara no finalitzada Guerra de Successió.

No finalitzaria ací la relació simbòlica entre Miquel i els Borbons. El 25 de febrer del 1724, amb motiu de la processó per la proclamació del rei Lluís I, el gremi de Confiters alçà una estructura efímera en forma d'Atles, junt al mur del convent de Santa Tecla. En la part superior del mateix col locaren una figura de l'arcàngel com a defensor de la corona d'Espanya. ${ }^{19}$ Fins i tot, un segle després de les victòries de Felip V a la guerra de Successió, la participació patrocinadora de l'arcàngel

19 Relacion individual de la celebre función que celebró la Muy Ilustre, y Fidelissima Ciudad de Valencia, en la Jura solemne, que el dia 24. de Febrero hizo á la Magestad de Nuestro Rey, y Señor Don Luis Primero (el Deseado) y de la Solemnisima Procesion de gracias que se hižo en esta dicha Ciudad el dia siguiente 25, València, 1719, pàg. 4.

SCRIPTA, Revista internacional de literatura i cultura medieval i moderna, núm. 17 / juny 2021 / pp. 117-138 ISSN: $2340-4841 \cdot$ doi:10.7203/SCRIPTA.17.20735 
Enric Olivares Torres. La imatge triomfal de sant Miquel i la propaganda del poder en la cultura festiva. Història de les festes d'acció de gràcies celebrades a València el 1711 per les victòries felipistes a Brihuega i Villaviciosa durant la Guerra de Successió.

en favor dels cristians encara es mantindria en precs formulats davall aquesta volunta protectorat, com ara en la Oración a S. Miguel arcángel por el Reyno de España, composta pel pare fra Diego Joseph de Cadiz a València el 1808, o la Oración al Príncipe de los Ángeles san Miguel Arcángel, por las necesidades de España, persona del Rey Nuestro Señor, y sus Exércitos, dedicada al rei Ferran VII.

\section{Conclusions}

En la cultura festiva barroca la visualitat és l'element dominant. No hi ha més que recordar aquelles llargues processons en què les imatges devocionals, ricament vestides i carregades de joies i pedreria, eren transportades per volants abillats amb les més diverses formes i precedides per les banderes $\mathrm{i}$ les danses rituals dels gremis. Però també els carros de triomf, espectaculars i impressionants, són usats amb sentit propagandístic per tal d'explotar la idea de la victòria. Uns seguicis tan lluïts i plens d'inventiva que enlluernaven el públic tant com ho feia el luxe amb què es decoraven els temples o el barroquisme persuasiu i retòric dels altars efímers i arcs de triomf que poblaven la volta de la processó.

El ritual festiu tenia com a finalitat mostrar la natura i la representació del poder. Des de l'amenitat i l'espectacle, les festes, ja foren polítiques o religioses, es convertiren en un subtil i eficaç mecanisme d'expressió del poder, de legitimació d'aquest i de difusió dels valors i els ideals dels seus detentadors. No és estrany, per tant, que en aquelles celebracions de gràcies que em estudiat, el principal motor de les mateixes fora la glorificació de la monarquia i el seu poder absolut. La literatura, però també la visualitat festiva, seran les encarregades d'exaltar el seu paper com a principal garant de la religió vertadera. Així, a través de la imatge i la paraula observem un recolzament de les idees polítiques i morals predominants, en favor de les quals s'utilitzarà més la persuasió indicativa que la lògica demostrativa.

Pràcticament, la totalitat de les manifestacions festives analitzades apunten cap a un objectiu predominant: l'exaltació del poder reial, el qual s'explicita una i altra vegada en la voluntat per demostrar la fidelitat de la ciutat i regne de València cap al monarca com a defensor de la vertadera fe i com a principal beneficiari de la intercessió de la providència, a través de les figures de la Mare de Déu i l'arcàngel sant Miquel, en tan sagrada missió. Molt especialment, aquest últim, amb el qual s'estableix una connexió simbòlica a través de la visualitat i la literatura, i en la que Felip V és representat com un alter ego del príncep de la milícia celestial. 
Enric Olivares Torres. La imatge triomfal de sant Miquel i la propaganda del poder en la cultura festiva. Història de les festes d'acció de gràcies celebrades a València el 1711 per les victòries felipistes a Brihuega i Villaviciosa durant la Guerra de Successió.

\section{Bibliografia}

Alenda y Mira, Jenaro (1903), Relaciones de solemnidades y fiestas públicas de España, Madrid, Sucesores de Ribadeneyra.

Alonso Asenjo, J. (2002), «Alcides alegórico: Máscara o mojiganga estudiantil por el triunfo de Felip V en Villaviciosa (1710)», Scriptura, 17, pp. 7-32.

Arroyo, S. de (1711), Prodigio philipico y Deo gratias mercedario que en la solemne fiesta de acción de gracias que hizo el Real Convento Casa Grande de Nra. Sra. de la Merced Redención de cautivos de la Ciudad de Sevilla, en desagravios del Santísimo Sacramento y por la feliz victoria que consiguieron las armas católicas de N. Rey y Señor Don Felipe V (gue Dios guarde) en el campo de Bribuega ..., Francisco de Garay, Sevilla.

Bacallar y Sanna, V. (1957), Comentarios de la Guerra de España e historia de su rey Felipe V, el Animoso (a cura de C. Seco Serrano), Madrid, Atlas.

Borreguero Beltrán, C. (2003), «Imagen y propaganda de guerra en el conflicto sucesorio (17001713)», Manuscrits. Revista d'història moderna, 21, pp. 95-132.

Bouza Álvarez, F. (2008), Papeles y opinión. Politicas de publicación en el Siglo de Oro, Madrid, CSIC.

Cabrera, A. (1708), Glorias de el señor D. Felipe Quinto... y fatales consequencias..., Madrid, Francisco Antonio de Villa-Diego.

Carreres Zacarés, S. (1925), Ensayo de una bibliografía de libros de fiestas celebradas en Valencia y su antiguo Reino, València, Imprenta Hijo de F. Vives Mora.

Castellví, F. De (2002), Narraciones históricas (ed. a cura de J. M. Mundet i Gifré i J. M. Alsina i Roca), Madrid, Fundación Francisco Elías de Tejada, vol. III.

Castro, F. A. de (1711), Alcides alegórico. Idea con que celebró la Escuela de Estudiantes del Colegio de San Pablo de esta Ciudad de Burgos la feliz victoria que consiguieron las Armas de nuestro glorioso Monarca Don Felipe V el Animoso (que Dios guarde) de las Armas de los Aliados en los Campos de Villaviciosa..., Burgos, Juan de Bihar.

Catalá Gorgues, Miguel Ángel (2013), Ángeles y demonios en Valencia. Su proyección socio-cultural y artística, València, Reial Acadèmia de Sant Carles, 2 vols.

Cervera, J. (1707), Oracion evangelica, en la solemnissima fiesta, que la Santa Metropolitana Iglesia de Valencia celebrò en Accion de gracias à Dios nuestro Señor, à Maria Santissima de los Desamparados y à todos los Santos Patronos, que asistieron à nuestro Catolico Monarca Felipe V. assi en la feliz V itoria del dia 25. de Abril, como en la justa Recuperacion de Valencia dia 8. de Mayo del presente año 1707, València, Antonio Bordázar.

Cruilles, marqués de (1876), Guía urbana de Valencia antigua y moderna, I, València, Imprenta de José Rius.

Cubero Tirado Ramírez de Arellano, J. (1711), Triunfos del Sacramento y María conseguidos en la feliz. victoria que obtuvieron las Católicas Armas de nuestro Animoso Rey Felipe V (que Dios guarde) sobre el campo de Villaviciosa..., Burgos. 
Enric Olivares Torres. La imatge triomfal de sant Miquel i la propaganda del poder en la cultura festiva. Història de les festes d'acció de gràcies celebrades a València el 1711 per les victòries felipistes a Brihuega i Villaviciosa durant la Guerra de Successió.

Escartí, V. J. (2007), ElDiario (1700-1715) de Josep Vicent Ortí i Major. Estudi i edició, València, Bancaixa.

Fité, F. (1996), «La imatge arquetípica de sant Miquel entre Orient i Occident i la seva incidència a Catalunya», dins Bérchez, J. / Gómez-Ferrer, M. / Serra, A. (coord.), El Mediterráneo y el Arte español. Actas del XI Congreso de Historia del Arte, València, Generalitat Valenciana, pp. 19-26.

Garcia, F. (1684), El primer ministro de Dios, san Miguel Arcángel, consagrado a la emperatriz de los Cielos y de la tierra María, Madre de Dios, Madrid, Juan García Infançon.

Jordán, J. (1704), Historia de la provincia de la Corona de Aragón de la sagrada orden de los ermitaño de Nuestro Gran Padre san Agustin, València, Joseph García.

Laguno, F. De (1710), Oración panegirica en la solemne acción de gracias que celebró en el convento de San Agustín de Pamplona a Nuestra Señora del Pilar... por las felices victorias que en los días 9 y 10 de dicho mes consiguió N. Católico y amado Rey el Señor Don Felipe V ..., Pamplona, Francisco de Neyra.

Ledda, G. (2000), «Estrategias y procedimientos comunicativos en la emblemática aplicada (fiestas y celebraciones, siglo XVIII)», dins Zafra, R. i Azanza, J. J., Emblemata aurea. La emblemática en el arte y la literatura del Siglo de Oro, Madrid, Akal, pp. 251-262.

Llorente Olivares, T. (1887), Valencia. Sus monumentos y sus artes, su naturaleza y su historia, Barcelona, Daniel Cortezo.

Madrid, F. De (1710), Sermón de gracias, reducido a dolores gloriosos. Predicado ... en la parroquia de la Magdalena de la Ciudad de Toledo, en ocasión de felices y repetidas victorias ... en el Asalto de Bribuega y Batalla de Villaviciosa ..., Toledo, Agustina de Salas.

Martínez Gil, F. (2011), «Los sermones como cauce de propaganda política: la Guerra de Sucesión», Obradoiro de Historia Moderna, 20, pp. 303-306.

Mínguez, V.; González, P. y Rodríguez, I. (2010), La Fiesta Barroca. El Reino de Valencia (1599-1802). Triunfos Barrocos, Castelló de la Plana, Universitat Jaume I, vol. I.

Monteagudo Robledo, Ma P. (1995), El espectáculo del poder. Fiestas Reales en la Valencia Moderna, València, Ajuntament de València.

Morán Turina, M. (1990), La imagen del Rey: Felipe V y el Arte, Madrid, Nerea.

Nieremberg, J. E. (1643), Devocion, y patrocinio del Patrón de la Iglesia, y de los dominios de España, el glorioso arcángel San Miguel, Madrid, Francisco de Robles.

Olivares Torres, E. (2015), L'ideal d'evangelització guerrera. Iconografia dels cavallers sants, tesi doctoral dirigida per Rafael Garcia Mahíques, València, Universitat de València.

Olivares Torres, E. i Trescolí Bordes, O. (2017), «Ball dels tornejants. Passat i present d’una dansa valenciana», Patrimoni Immaterial. Experiències en el territori valencià, València, Universitat de València, pp. 65-75.

Ortí y Mayor, J. V. (1711), Demonstraciones festivas, que los leales afectos à su Magestad bizieron dia de los Reyes del presente año 1711. en la Procession Solemne, que se hizo en gracias del feliz. triunfo que ganò... Don Felipe V el Animoso, en la fortunada expedicion de Bribuega, y Batalla de Villaviciosa, València. 
Enric Olivares Torres. La imatge triomfal de sant Miquel i la propaganda del poder en la cultura festiva. Història de les festes d'acció de gràcies celebrades a València el 1711 per les victòries felipistes a Brihuega i Villaviciosa durant la Guerra de Successió.

Ortí y Mayor, J. V. (1715), Diario de lo sucedido en la ciudad de Valencia desde el día 3 del mes de octubre del año de 1700 hasta el día $1^{\circ}$ del mes de septiembre del año de 1715.

Ortí y Moles, J. (1710), Resumen de las catolicas y leales correspondencias de Valencia, à los varios sucessos de la Reales armas del Rey nuestro Señor de 20 de agosto y 9 y 10 de diziembre 1710, València.

Ortí, J. (1740), Historia del Hallazgo de la imagen de S. Christóval..., València.

Pedraza, P. (1982), Barroco efímero en Valencia, València, Ajuntament de Valencia.

Pérez Picazo, Mª T. (1996), La publicistica española en la Guerra de Sucesión, Madrid, CSIC, 2 vols.

Pingarrón, F. (1998), Arquitectura religiosa del siglo XVII en la ciudad de Valencia, València, Ajuntament de València.

Planes, I. (1899), Sucessos fatales desta ciudad, y Reyno de Valencia, o Puntual Diario de la sucedido en los años de 1705, 1706 y 1707, València.

Puigpardines, B. de (2000), Sumari d'Espanya, (ed. a cura de J. Iborra), València, Universitat de València, València, vol. III.

Teixidor, J. (1895), Antigüedades de Valencia, II, València, Librería de Pascual Aguilar.

Tovar, S. de (1643), Memorial dado a la Católica Magestad del Rey nuestro Señor don Felipe III sobre la invocacion y devocion del glorioso Arcángel San Miguel Capitán General de los exércitos del Cielo, Madrid, Juan Sánchez.

Ubieto Arteta, A. (1999), Leyendas para una historia paralela del Aragón medieval, Zaragoza, Instituto Fernando el Católico, Zaragoza.

Wittlin, Curt, Introducció a Eiximenis, F. (1983), De Sant Miquel Arcángel, Barcelona, Curial.

Ximeno, V. (1747), Escritores del reyno de Valencia, València, Josep Esteban Dolz, vol. II. 